\title{
Caminhos e descaminhos do pensamento brasileiro
}

\author{
The directions and misdirections \\ of Brazilian thought
}

\author{
Isabel Lustosa \\ Pesquisadora da Fundação Casa de Rui Barbosa \\ Rua São Clemente, 134 \\ 22260-000 - Rio de Janeiro - RJ Brasil
}

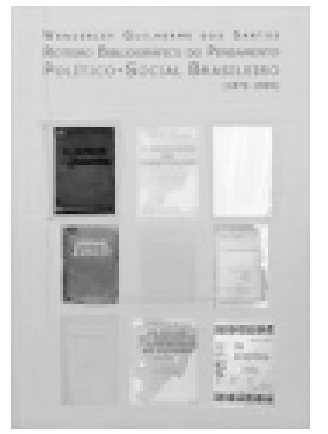

Wanderley Guilherme dos Santos

Roteiro bibliogáfico

do pensamento

politico-social brasileiro

(1870-1965)

Editora UFMG/Casa de

Oswaldo Cruz, 2002,

267p.
$\mathrm{N}$ este livro estão reunidos dois trabalhos de Wanderley Guilherme dos Santos. Um é o Roteiro bibliográfico do pensamento políticosocial brasileiro (1870-1965), levantamento das principais obras do pensamento brasileiro, realizado há 36 anos e nunca antes publicado; o outro é uma reflexão sobre nossa história das idéias e já se tornou um texto clássico: Paradigma e história: a ordem burguesa na imaginação social brasileira. O levantamento bibliográfico fala por si mesmo. No entanto, vale a pena ressaltar a originalidade dos critérios de seleção que o orientaram. Concebida originalmente em 1966 para orientar uma pesquisa sobre a Imaginação político-social brasileira, a seleção bibliográfica privilegiou fontes e temas em que se evidenciava a forte relação entre história política e história intelectual e concentrou-se nos estudos cuja ênfase recai sobre questões econômicas e sociais. Aliado a Paradigma e história, trabalho nele baseado, esse Roteiro bibliográfico é ferramenta indispensável para os que se dedicam ao estudo da história do pensamento social brasileiro.

Paradigma e história, por sua vez, é um dos textos mais inteligentes que já se escreveram no Brasil. De forma precisa e ao mesmo tempo abrangente, Wanderley Guilherme dos Santos conseguiu contemplar, os grandes temas da história de nossas idéias, relacionando-os com as evoluções da nossa vida política. Ao fazer a crítica das leituras que as ciências sociais vinham fazendo sobre a trajetória desse mesmo pensamento, Wanderley Guilherme dos Santos também abriu um filão inesgotável de debate com seus pares. Provocante e criativo, o texto, escrito há mais de 25 anos, continua a ser a crítica mais ousada que já se fez aos métodos e práticas das ciências sociais no Brasil. O que surpreende ao leitor de hoje em dia, depois das tantas transformações teóricometodológicas por que passaram as ciências humanas - história e antropologia, à frente, impulsionadas pela boa comunicação que estabeleceram entre si e com os estudos de literatura e de psicanálise é como as críticas ainda resplandecem em sua atualidade.

Talvez Wanderley Guilherme dos Santos tenha usado de certa malícia ao republicar Paradigma e história. Malícia e humor, de resto, que sempre foram marcas de seu estilo de escrever e pensar, mantendo sua ciência ao abrigo da pompa e do formalismo. A ironia que preside algumas de suas mais densas análises não se confunde, no entanto, com o ceticismo estéril que vem assolando de forma ruinosa as ciências humanas de nosso 
tempo. Ceticismo que, aliado ao uso irresponsável e acrítico do politicamente correto e do desconstrucionismo, tirou força e substância das ciências sociais, sem lhes dar nada em troca. A ironia de Wanderley Guilherme, ao contrário, sempre teve um sentido crítico e apresentou-se de forma positiva.

A malícia de se publicar Paradigma e história hoje reside no fato de que o texto nos revela a aguda percepção que o autor tinha das possibilidades do quadro político e intelectual em que escrevia. Se sua restrição ao que chamou de "convencionalismo às vezes solene porém não menos banal do marxismo acadêmico" antecipou em muitos anos as críticas de mesmo teor que se tornariam elas mesmas banais nas décadas de 1980 e 1990, a antecipação, neste texto, do destino das diversas tendências então atuantes na cena política brasileira dálhe foros de vidente. Pois Wanderley já sabia, naqueles idos de 1975, que as camadas superiores da sociedade eram "contrárias à expansão do poder público e de sua capacidade de definir a hierarquia dos objetivos sociais fora dos mecanismos do mercado".

$\mathrm{Na}$ ditadura, diz Wanderley, o governo impedira que "o privatismo monopolizasse completamente as instituições políticas e que organizações doutrinárias ensaiassem uma estratégia revolucionária de mudança social". Com isso, os que acreditavam que o Estado era o meio mais adequado para a instauração da ordem social burguesa passaram a demandar a implantação de instituições liberais clássicas, em que necessariamente teriam predominância os interesses burgueses privados. Naquele contexto, o caminho certo consistiria em "restituir os direitos civis e políticos que já faziam parte do patrimônio da civilização, sem entretanto permitir que o privatismo predatório, sob a propaganda do humanismo libertário, se apropriasse dos mecanismos de decisão". Tratava-se de identificar e seguir uma linha sutil que transcendesse "os limites da ordem privada em qualquer de suas variantes" e escapasse das "conceituações fáceis e estereotipadas do revolucionarismo acadêmico".

Partindo do pressuposto de que as ciências sociais brasileiras se constituíram pela influência tanto dos avanços teóricos e metodológicos gerados no exterior quanto da história econômica, social e política do país, Wanderley Guilherme dos Santos orienta seu argumento em três direções. Primeiro, analisando as diversas tradições pelas quais se convencionou definir o que era e o que não era ciência social na história de nossas idéias; segundo, questionando a tendência, dentro dessa mesma história, de apresentar o problema brasileiro como o produto de contrastes dicotômicos; e terceiro, definindo como o grande motor para a produção desse pensamento social, desde a independência, o propósito de fazer estabelecer entre nós a ordem burguesa.

Para desenvolver a primeira dessas abordagens, Wanderley Guilherme dos Santos define três matrizes com as quais o pensamento social brasileiro vem sendo tratado. A matriz institucional estabeleceu como marco do início da produção de trabalhos científicos na área a data da institucionalização dos cursos de ciências sociais no Brasil, o que teria acontecido em torno dos anos 1930. A matriz sociológica, por sua vez, explicaria as variações ocorridas no conteúdo das preocupações dos investigadores sociais a partir das características da estrutura econômico-social, ou, em sua versão mais simplória, estabelecendo uma relação de causalidade 
necessária entre "os atributos ou dimensões do pensamento social e os atributos e dimensões do processo social". Na opinião de Wanderley Guilherme, esse tipo de correlação forçada, automática, estaria na direção inversa da verdadeira produção de conhecimento, que consistiria "em garantir distinções significativas cada vez mais nuançadas e finais, permitindo perceber a diferença, o diverso ali onde a visão deseducada vê apenas a mesma coisa".

Wanderley Guilherme dos Santos lembra que, desde a independência, o Brasil produz reflexão sobre sua ordem social e política e sobre seu lugar no mundo, não influindo na qualidade dessas reflexões o fato de nos faltarem instituições especializadas. As razões por que as matrizes institucional e sociológica se tornaram hegemônicas foram: o cerceamento da liberdade de pesquisa e reflexão durante o Estado Novo, impedindo o contato das novas gerações com a história crítica do passado; e a influência das inovações metodológicas e conceituais trazidas pelos professores estrangeiros que implantaram aqui os cursos de ciências sociais, durante as décadas de 1930 e 1940. Com isso fixou-se a idéia de que não havia tradição acadêmica em estudos políticos e sociais, não se podendo portanto estabelecer uma continuidade entre o pensamento político social brasileiro contemporâneo e o produzido no passado próximo.

Se as duas matrizes acima são facilmente identificáveis com a tradição da qual Florestan Fernandes foi o grande formulador, a terceira, chamada de matriz ideológica e cujo formulador é Guerreiro Ramos, aponta para soluções mais criativas. A matriz ideológica tem como objetivo buscar a caracterização conceitual própria dos textos sociais brasileiros, sem fazêlos depender necessariamente da conjuntura em que foram produzidos. Ao se libertar das amarras cronológicas que marcam a matriz institucional, e sem cair na tentação de classificar os autores e sua obra a partir exclusivamente das circunstâncias em que escreveram, essa matriz é capaz de estabelecer relações entre as maneiras de pensar de autores do passado com os do presente. Ou, como diz Wanderley Guilherme: dessa perspectiva, o fato de ter nascido no século XIX não condenaria ninguém "a ser um fracassado postulante ao ingresso na comunidade acadêmica". Com o instrumental de análise proposto por Guerreiro Ramos é possível também revelar tradições que se estabeleceram ao longo de nossa história das idéias.

Uma dessas - e é este o segundo eixo da digressão de Wanderley Guilherme dos Santos - é a tendência a pensar a realidade do país como uma dicotomia. Tal paradigma parte da pressuposição de que existe um conjunto de atributos que não podem existir senão simultaneamente. Estabelecido por Euclides da Cunha, ao contrastar a realidade do Brasil sertanejo com a do Brasil urbano, o paradigma obedecia à seguinte seqüência: descobrir uma dicotomia; traçar a formação da dicotomia no passado histórico nacional; propor a alternativa política à dicotomia. Nossa dicotomia, ainda de acordo com o mesmo paradigma, teria se formado durante o século XIX e seria a fonte dos nossos principais problemas. O fato de este paradigma ter-se estabelecido como base das principais análises da realidade brasileira desde o começo do século XX leva Wanderley Guilherme a questionar o porquê da insistência nas dicotomias, polaridades 
e tensões. "Segundo que registro o acontecer simultâneo e sucessivo da história cotidiana se organiza e reproduz conceitualmente sob a forma de oposições consteladas?", ele pergunta. Talvez porque a dicotomização seja o caminho mais fácil para embarcar em outro paradigma: o da inadequação. Separados: mar e sertão, casa e rua, país legal de país real, cidades partidas, tudo parece indicar que havia um caminho certo em que essas duas partes acabariam por formar um todo. Em algum momento de nossa história nos desviamos desse arranjo ideal.

Finalmente chegamos à última das teses de Paradigma e história e recuperamos outra tradição do pensamento social brasileiro. Afirma Wanderley Guilherme que, desde a independência, o problema de nossas elites políticas e intelectuais tem sido como implantar e garantir o eficiente funcionamento da ordem liberal e burguesa no Brasil. O debate em torno da forma que assumiria o Estado no Brasil independente foi balizado na questão que marcou todo o século XIX, do Primeiro Reinado até a proclamação da República: centralização ou descentralização. A pressão das províncias por mais autonomia e a contrapressão do governo do Rio de Janeiro, no sentido de garantir a unidade nacional e a concentração do poder nas mãos do imperador, estiveram na origem dos principais conflitos internos que agitaram o Brasil desde a Confederação do Equador (1824). Mas o tema implícito, o tema tabu, aquele sobre o qual pouco se falava, mas que definia o destino de tudo, pairando sobre as cabeças dos que faziam a política do país foi, desde o primeiro momento, o da escravidão.

Wanderley Guilherme vê mais bom senso e imaginação sociológica nos políticos conservadores do Império do que nos liberais. Pois os liberais acreditavam que era viável, num Brasil escravocrata, a constituição de uma sociedade liberal semelhante à inglesa e à norte-americana, e que a implantação do federalismo agilizaria automaticamente as atividades do Estado. Wanderley lembra que qualquer ordem social não ocorre naturalmente, mas resulta da ação política coordenada, e que a eficácia das instituições depende da ordem social e política que as envolve. Caberia, portanto, ao poder político existente manter e eventualmente criar a ordem que correspondesse às preferências dominantes. A crítica que faz à postura dos liberais do Império, a crença em que "as mesmas instituições produzem necessariamente os mesmos efeitos políticos, independentemente da ordem que em que se inserem", é do mesmo teor da que faz às matrizes institucional e/ou sociológica acima citadas. Wanderley desconfia de "qualquer doutrina ou postura que considere possível a realização imediata de qualquer conjunto de preferências políticas independente da mediação institucional".

O debate entre centralização e descentralização do Brasil já aparecera como tema nas Cortes de Lisboa, por meio do documento que a elas enviou José Bonifácio de Andrada. Este e os que pensavam como ele que, no Segundo Reinado estão representados no artigo de Wanderley Guilherme por Paulino Soares de Sousa - compreendiam que, "dadas as condições do escravismo quase auto-suficiente", os diversos 'localismos' dificilmente se integrariam por meio de interações econômicas e sociais naturais. Sabiam que "uma ordem social não se estabelece a partir do vazio, ou de um hipotético estado de natureza, sem regras, comando ou 
subordinações, mas se impõe sempre a outra ordem que a precede". A questão no Brasil, portanto, onde a ordem existente era a escravocrata, não consistia apenas em promover, na lei, a existência de instituições liberais, mas de impô-las à ordem escravista existente. "E quem iria impôla senão o poder estatal?", pergunta Wanderley.

Esta foi, aliás a razão da polêmica em torno dos limites do poder do imperador, nos jornais brasileiros de 1822 e nos debates da naufragada Constituinte de 1823. José Bonifácio dizia que os que queriam que, no Brasil, logo após a partida do rei, se implantasse um parlamento nos moldes da França revolucionária eram "homens alucinados por princípios metafísicos e sem conhecimentos da natureza humana, que queriam criar poderes impossíveis de sustentar". Gente como José Bonifácio e Paulino Soares de Sousa sabia que, para constituir uma ordem privada burguesa no Brasil, era preciso primeiro "dotar o poder político dos instrumentos que lhe permitam instaurá-la e sustentá-la, o que queria dizer, no Brasil do século XIX, expandir a capacidade reguladora do Estado pela criação de um aparelho administrativo nacional, subordinado a um comando único, e pela redução do centrifugismo local, obrigando-o a integrar-se por via do Estado". Aspecto importante desse texto multifacetado é a análise que Wanderley Guilherme faz do Iseb, espaço em que ele mesmo produziu e publicou suas primeiras obras. Destacando a importância daquele organismo na divulgação de vários temas importantes para a compreensão dos problemas brasileiros, Wanderley procura, no entanto, situar o próprio Iseb na tradição sociológica brasileira, lembrando que o instituto apenas poliu e deu nova formulação a idéias que já vinham sendo trabalhadas desde o Império. Não pretende com isso desvalorizar a contribuição do Iseb, mas situá-lo num contexto histórico e também chamar a atenção - não sem uma certa ironia - para o fato de que diversas linhas de exploração abertas pelos estudiosos do passado permanecem inexploradas, "a espera de continuidadores ou de quem as repita com sabor de novidade".

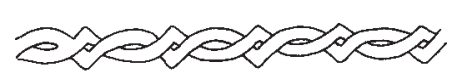




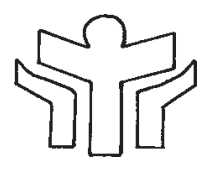

